\title{
Desempenho de Enlace VLC com Modulação OOK e OFDM sob Condições Adequadas de Iluminação
}

\author{
David Esteban Farfán Guillén, Paulo de Tarso Neves Jr e Alexandre de Almeida Prado Pohl
}

Resumo-A comunicação em luz visível (Visible Light Communication - VLC) transmite dados por meio de diodos emissores de luz. Neste trabalho é implementado um sistema de comunicação VLC com o uso de uma lâmpada comercial composta por 7 LEDs brancos. $\mathrm{O}$ sistema inclui o projeto e a montagem dos circuitos eletrônicos do sistema de transmissão e recepção. As diferentes simulações realizadas para um ambiente interno mostram que sistemas VLC podem transmitir dados enquanto mantém uma iluminação adequada. As modulações OOK e OFDM são usadas para transmissão de dados $\left(B E R \leq 10^{-3}\right.$ para distâncias de até $d \geq 1,7 \mathbf{~ m}$ ). Para a caracterização das condições de iluminação são realizadas medidas fotorradiométricas, garantindo iluminação adequada até $1,6 \mathrm{~m}$.

Palavras-Chave - Comunicação em luz visível, Diodo emissor de luz, Fotodiodo, Interno, Recepção, Transmissão.

Abstract - Visible light communications (VLC) transmit data through light emitting diodes. In this work, a VLC communication system is implemented with a commercial lamp composed of 7 white LEDs. The system includes the design-assembly of the electronic circuits of the transmission and reception front-ends. The different simulations carried out for an indoor environment show that VLC systems can transmit data while also maintaining the adequate lighting condition. OOK and OFDM modulations are used for the data transmission $\left(B E R \leq 10^{-3}\right.$ for distances up to $d \geq 1,7 \mathbf{m}$ ). To characterize the illumination condition, photoradiometric measurements are made, ensuring adequate lighting up to $1,6 \mathrm{~m}$.

Keywords - Indoor, Light emitting diode, Photodiode, Reception, Transmission, Visible light communication.

\section{INTRODUÇÃO}

No cenário atual há um número cada vez maior de usuários que se ligam à rede devido à popularização da internet e há oferta crescente de dispositivos eletrônicos das mais variadas gamas que integram a conectividade. Isto tem gerado uma demanda crescente tanto por maior velocidade de transmissão de dados quanto por bandas espectrais para poder transmití-los [1].

A comunicação sem fio obteve um grande desenvolvimento e crescimento nas últimas décadas e pode ser classificada como comunicação em radiofrequência (Radio Frequency - RF) e comunicação ótica sem fio (Optical Wireless Communication - OWC) [2].

À medida que o tráfego de dados aumenta exponencialmente as limitações na comunicação RF têm sido identificadas.

David Esteban Farfán Guillén, e-mail davides.far@gmail.com, Paulo de Tarso Neves Jr, e-mail: pneves@utfpr.edu.br, e Alexandre de Almeida Prado Pohl, e-mail: pohl@utfpr.edu.br, estão com o Programa de Pós-Graduação em Engenharia Elétrica e Informática Industrial, CPGEI, Universidade Tecnológica Federal do Paraná, Curitiba-PR. Este trabalho foi parcialmente financiado pelo CNPq (processo 305714/2016-3). Os autores agradecem o Laboratório Multiusuário de Fotônica - Câmpus Curitiba
Mesmo com uma repartição eficiente das frequências, o espectro atual revela-se limitado para a elevada demanda de conectividade, podendo desencadear o congestionamento nas redes e exigindo alternativas que possam solucionar uma futura diminuição na qualidade de serviço. Uma alternativa viável para atender estes requisitos é a OWC [3].

A comunicação em luz visível faz parte das comunicações óticas sem fio e é considerada como uma solução eficiente, econômica e ecológica que explora a infraestrutura de iluminação existente para transmitir dados usando diodos emissores de luz (Light Emitting Diode - LED) na faixa de $380 \mathrm{~nm}$ a $750 \mathrm{~nm}$, o que corresponde ao espectro visível da luz [2].

$\mathrm{O}$ sistema VLC tem um espectro na faixa de THz, apresentando uma largura de banda que, ao contrário da comunicação por RF, ainda não exige licenciamento. Isso facilita a sua utilização como alternativa à crescente procura de velocidade nas redes de comunicação, apresentando-se como uma tecnologia compatível com as redes existentes e as redes de nova geração em desenvolvimento [3].

A comunicação VLC pode servir como complemento aos sistemas de comunicação móvel em RF através da concepção e implementação de redes de alta capacidade. Além disso podese desenvolver células de transmissores LED para ambientes internos iluminados, conferindo uma alternativa para comunicações de alta velocidade [4].

Diferentes investigações têm sido realizadas sobre VLC, concentrando-se principalmente na velocidade de transmissão de dados usando diferentes técnicas; trabalhos recentes relatam velocidades de transferência em torno de Gbps, embora para distâncias muito curtas [5]. Além disso, a aplicação do VLC tem sido estudada em diferentes tipos de comunicações, como 5G [6], LTE (Long Term Evolution) [7] e comunicação veicular [8].

No entanto, ainda existem questões a serem investigadas e desafios a superar, como a aplicabilidade dos LEDs disponíveis no mercado como fontes para o sistema VLC. Neste trabalho foi empregada uma lâmpada LED comercial de luz branca para uso em comunicação ótica sem fio [9]. Um enlace VLC foi configurado, mantendo-se simultaneamente as condições adequadas de iluminação para um ambiente interno. Para a transmissão de dados foram usadas a modulação OOK (Onoff keying) e OFDM (Orthogonal Frequency Division Multiplexing), avaliando-se o desempenho do enlace no receptor por meio da taxa de erro de bit (Bit error rate - BER) versus distância em um cenário com linha de visada (Line of sight LOS). As características de iluminação da lâmpada empregada para diferentes potências elétricas foram relacionadas com o desempenho do canal de comunicação para se encontrar o ponto de funcionamento otimizado do sistema. 
O artigo foi organizado da seguinte forma: a Seção II trata da caracterização do canal ótico sem fio para sistemas VLC. A seção III apresenta o projeto dos circuitos eletrônicos do sistema de transmissão (Tx) e recepção (Rx). A seção IV apresenta os resultados experimentais e sua análise. A seção $\mathrm{V}$ descreve as conclusões.

\section{CANAL Ótico VLC}

O diagrama de blocos do sistema VLC é mostrado na Fig. 1 e consiste em um sinal de dados que é modulado e transmitido pelo bloco transmissor. $\mathrm{O}$ sinal se propaga pelo espaço livre assumindo-se um cenário do tipo LOS. No bloco receptor o sinal é recebido e demodulado, recuperando-se os dados transmitidos [10].

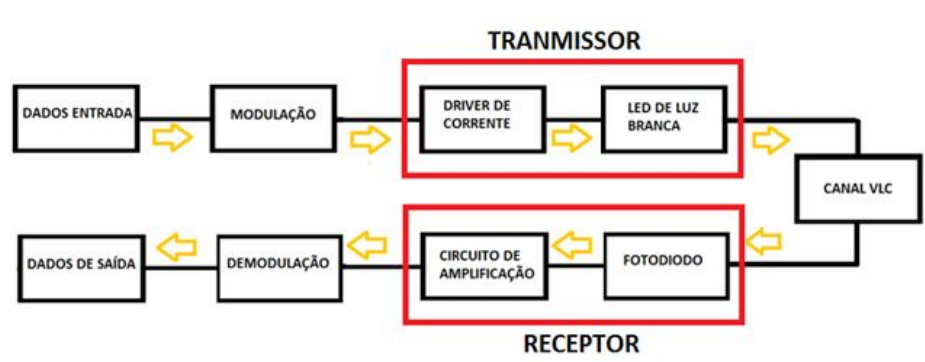

Fig. 1. Diagrama de blocos do sistema VLC

O canal ótico VLC é assumido como linear, invariante no tempo e sem memória. Para a transmissão utiliza-se uma técnica de modulação por intensidade e detecção direta (IM/DD), onde a intensidade da corrente é proporcional à integral da potência ótica capturada em toda a área do fotodiodo. Assumese também que a transmissão apresenta desvanecimento lento, em razão de o comprimento de onda do sinal ser menor do que a área do fotodetetor [11].

Em um enlace VLC empregado em ambientes internos o ruído pode ser representado como um ruído branco aditivo gaussiano (Additive White Gaussian Noise - AWGN) [12]. Por conseguinte, tal enlace pode ser descrito como:

$$
y(t)=h(t) * R \cdot x(t)+n(t),
$$

onde $*$ representa convolução linear, $y(t)$ é o sinal recebido depois de ter passado pelo canal ótico sem fio e acrescido ao ruído, $x(t)$ é o sinal transmitido, $R$ é a responsividade do fotodetetor, $h(t)$ é a resposta ao impulso do canal em banda base e $n(t)$ o ruído AWGN.

\section{A. Transmissor}

Enlaces OWC podem utilizar dois dispositivos como fontes emissoras: O LED e o diodo laser (LD). Para VLC, em ambientes internos o LED é a melhor opção, em razão de seu emprego praticamente consolidado em iluminação.

O LED é um elemento transdutor, ou seja, um dispositivo que transforma uma forma de energia de entrada (elétrica) em outra forma de energia de saída (luminosa) [13]. As fontes LED apresentam uma distribuição lambertiana, cuja distribuição espacial de intensidade é expressa por [14]:

$$
I(\phi)=I(0) \cos ^{m_{l}}(\phi),
$$

onde $\phi$ é o ângulo de radiação em relação ao eixo normal à superfície do transmissor, $I(0)$ é a intensidade luminosa máxima e $m_{l}$ é a ordem de emissão lambertiana. Por sua vez, $m_{l}$ é dada por [9]:

$$
m_{l}=-\frac{\ln (2)}{\ln \left(\cos \left(\phi_{1 / 2}\right)\right)}
$$

onde $\phi_{1 / 2}$ é o ângulo de meia potência do LED (também conhecido como semi-ângulo de meia-iluminação), no qual a intensidade da luz diminui para a metade da intensidade axial, condição esta conhecida como FOV (Field-of-View) [9].

\section{B. Receptor}

Os fotodetectores são transdutores que transformam a potência ótica recebida em um sinal elétrico, sendo que a corrente gerada pelo fotodetetor é proporcional ao quadrado do campo ótico incidente na superfície. O fator de conversão da luz recebida em corrente elétrica é conhecido como responsividade. $\mathrm{Na}$ recepção de sistemas VLC é utilizado um fotodiodo (PD) do tipo intrínseco (PIN) ou do tipo avalanche (APD) [10]. O fotodiodo detecta a potência ótica de forma proporcional à área efetiva de sua superfície. Para otimizar esta resposta pode-se colocar um concentrador ótico (lente) para aumentar a área efetiva de recepção, cujo resultado é expresso como [15].

$$
A_{e f f}(\alpha)=\left\{\begin{array}{ll}
A_{r} \cos (\alpha) g(\alpha) & 0 \leq \alpha \leq \psi \\
0 & \alpha>\psi
\end{array},\right.
$$

onde $A_{r}$ representa a área do detector, $\alpha$ é o ângulo de incidência para o eixo do receptor, $g(\alpha)$ é o ganho do concentrador e $\psi$ é o FOV do concentrador, sendo $\psi \leq \frac{\pi}{2}$.

A Fig. 2 representa o cenário LOS com um emissor LED lambertiano e um fotodiodo como receptor, onde $d$ é a distância entre o transmissor e o receptor, $r$ é o raio de abertura do receptor, $\alpha$ é ângulo de incidência (definido como o ângulo entre a linha normal ao receptor e a linha de visada direta entre o transmissor e o receptor) e $\phi$ é o ângulo de visão do feixe ótico radiado (definido como o ângulo entre a linha normal ao transmissor e a linha de visada direta). A potência recebida nesse sistema é dada por [16]:

$$
P_{r}=P_{t} \frac{A_{r}\left(m_{l}+1\right)}{2 \pi d^{2}} \cos ^{m_{l}}(\phi) \cos (\psi) g(\psi) \text {. }
$$

\section{Relação Sinal Ruído}

Em todo sistema é necessário determinar a relação entre o sinal e o ruído (Signal-to-Noise Ratio - SNR), já que esta determina a eficiência do enlace de comunicação; quanto maior for a SNR melhor será o desempenho do enlace. A SNR no canal ótico sem fio é proporcional ao quadrado do sinal de potência ótica recebido e é dada por [17]:

$$
S N R=\frac{\left(P_{r} R\right)^{2}}{\sigma_{\text {total }}^{2}},
$$

onde $P_{r}$ representa a potência ótica média recebida, $R$ é a responsividade do fotodiodo, $\sigma_{\text {total }}^{2}$ é a variância total do ruído dada por: 


$$
\sigma_{\text {total }}^{2}=\sigma_{\text {termico }}^{2}+\sigma_{\text {balistico }}^{2}
$$

Tal variância é representada pelo ruído balístico devido ao sinal incidente e à luz ambiente e pelo ruído térmico gerado no circuito de fotodetecção [17].

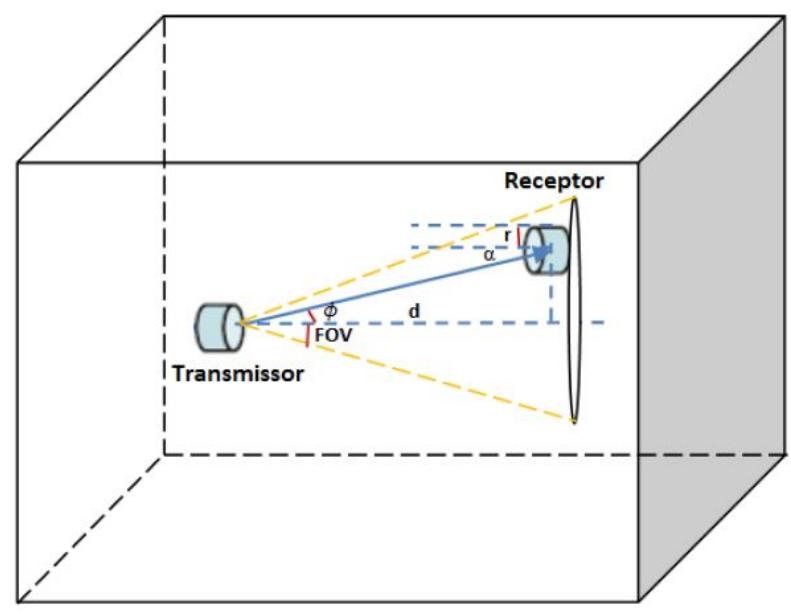

Fig. 2. Cenário LOS para um ambiente interno.

\section{Modulação ótica}

Para a transmissão dos dados foram utilizadas duas técnicas de modulação: modulação de portadora única e modulação de portadora múltipla [10]. Na modulação de portadora única foi empregada a técnica OOK, onde os bits 0 e 1 são transmitidos ligando e desligando o LED. Na modulação de portadora múltipla foi empregada a técnica de multiplexação por divisão de frequências ortogonais (OFDM), que utiliza subportadoras ortogonais para transmitir dados simultaneamente. Os dados são modulados por um esquema M-ário que pode ser M-QAM$\mathrm{N}$, onde $\mathrm{M}$ representa o número de símbolo e $\mathrm{N}$ o número de subportadoras [10].

As BERs das respectivas modulações OOK e OFDM são expressas por [18], [19]:

$$
B E R_{O O K}=Q \sqrt{S N R}
$$

$$
B E R_{O F D M}=\frac{4}{\log _{2} M} \cdot\left(1-\frac{1}{\sqrt{M}}\right) \cdot Q\left(\sqrt{\frac{3 \log _{2} M}{M-1} S N R}\right)
$$

sendo $\mathrm{Q}($.$) o fator de qualidade do enlace ( Q$-function).

\section{PROJETO DOS CIRCUitos ElETRÔNICOS TX-RX}

Esta seção trata do projeto do sistema de transmissão e do sistema de recepção.

\section{A. Transmissor - Tx}

Para o transmissor (Tx) foi projetado um circuito eletrônico que cumpre duas funções: transformar o sinal de dados de entrada em um sinal ótico de saída e proporcionar as condições para o funcionamento adequado da fonte LED. Dessa forma, deve-se projetar um circuito que atue como um controlador de corrente. A fonte utilizada consiste em um módulo Luxeon SP-02-T1SinkPAD-II com 7 LEDs de alta potência [9][20].

$\mathrm{O}$ circuito Tx emprega um driver de corrente (0-300 mA) com três estágios com transistores NPN que permitem controlar a corrente aplicada ao módulo para prover o desempenho da iluminação e a modulação de intensidade do LED. A transmissão de dados no Tx foi projetada para trabalhar na região linear do LED. Usando-se um analisador de rede, a resposta em frequência da placa do circuito $\mathrm{Tx}$, no ponto onde a amplitude do sinal é atenuada em $-3 \mathrm{~dB}$, foi medida em $50 \mathrm{MHz}$. Os dois primeiros estágios no esquema do Tx são circuitos de amplificação baseados em uma configuração de emissor comum, onde a impedância de saída é elevada. Para obter um melhor nível de estabilidade na saída, foi adicionado um terceiro estágio com uma configuração de retroalimentação, onde a impedância de saída é pequena.

\section{B. Receptor - Rx}

$\mathrm{O}$ circuito Rx é composto por um fotodiodo tipo PIN, pelos circuito de amplificação de transimpedância e os circuitos de ganho do sinal (3 estágios). O PD opera no modo fotocondutivo com polarização reversa. No circuito do Rx foi utilizado o fotodiodo Thorlabs FDS100 com área efetiva de $13 \mathrm{~mm}^{2}$.

Após receber o sinal luminoso e transformá-lo em corrente elétrica, é necessário converter a corrente em tensão para sua posterior recuperação. Para isso optou-se por um amplificador de transimpedancia (TIA). Após o TIA, foram incluídos três estágios de amplificação de ganho, de forma a se obter um sinal à saída do sistema, cujo valor apresente uma amplitude da ordem de volts. A resposta em frequência da placa do circuito $\mathrm{Rx}$, medida a $-3 \mathrm{~dB}$, foi de $50 \mathrm{MHz}$.

\section{ANÁlise EXPERIMENTAL}

Esta seção apresenta a avaliação das placas Tx-Rx e a análise de desempenho do enlace VLC tanto na iluminação quanto na transmissão de dados. $\mathrm{O}$ ensaio experimental foi realizado em um ambiente interno, em visada direta e com a luz ambiente desligada. As medições foram realizadas em uma mesa ótica com 2,2 $\mathrm{m}$ de comprimento e $0,97 \mathrm{~m}$ de largura.

\section{A. Enlace $T x-R x$}

O teste do enlace foi realizado posicionando-se sobre a mesa ótica o transmissor e o receptor alinhados em visada direta e afastados a uma distância de $2 \mathrm{~m}$ entre si. A Fig. 3 mostra o sinal recebido no $\mathrm{Rx}$, visto em um osciloscópio, quando uma onda quadrada de $1 \mathrm{MHz}$ de frequência é transmitida pelo Tx. Para avaliar o desempenho do circuito foi realizada a comparação com um módulo receptor comercial, Hamamatsu C12702-12 [21], que possui um APD com área de fododetecção de $7,1 \mathrm{~mm}^{2}$.

\section{B. Caracterização da luminária}

Para os experimentos foram realizadas medidas de espectro, potência ótica e luminância, para isso a lâmpada LED foi montada na mesa ótica. Com auxílio de um espectrômetro 
foi medida a distribuição espectral de potência da luminária. O ponto de máxima emissão foi caracterizado em $580 \mathrm{~nm}$.

Para estimar a potência ótica, foram realizadas medições entre a luminária (estrutura fixa) e um medidor de potência ótica (estrutura móvel) desde os $0,20 \mathrm{~m}$ até os 2,2 $\mathrm{m}$ com variações de $0,20 \mathrm{~m}$. Em cada ponto analisado a corrente elétrica controlada pelo Tx foi variada de 50 a $300 \mathrm{~mA}$ em passos de $50 \mathrm{~mA}$. No ensaio foi utilizado o sensor ótico modelo S121C, da Thorlabs, com área efetiva de $0,94 \mathrm{~cm}^{2}$.

Na Fig. 4 é observado o comportamento da potência ótica recebida em função da distância. Como exemplo, no caso em que a potência elétrica da lâmpada foi ajustada em $\mathrm{P}=6 \mathrm{~W}$ e o sensor colocado a uma distância de $2,2 \mathrm{~m}$, a potência ótica medida em tal ponto foi de $60,6 \mu \mathrm{W}$. Tal resultado foi obtido considerando-se uma área efetiva de $0,94 \mathrm{~cm}^{2}$ correspondente ao medidor de potência ótica. Entretanto deve-se calcular a potência ótica recebida pelo fotodiodo utilizado no Rx, que possui uma área de $13 \mathrm{~mm}^{2}$ e uma responsividade de 0,25 em $580 \mathrm{~nm}$. Fazendo-se tal estimativa, o valor calculado de potência ótica recebida no fotodiodo corresponde a $8,32 \mu \mathrm{W}$.

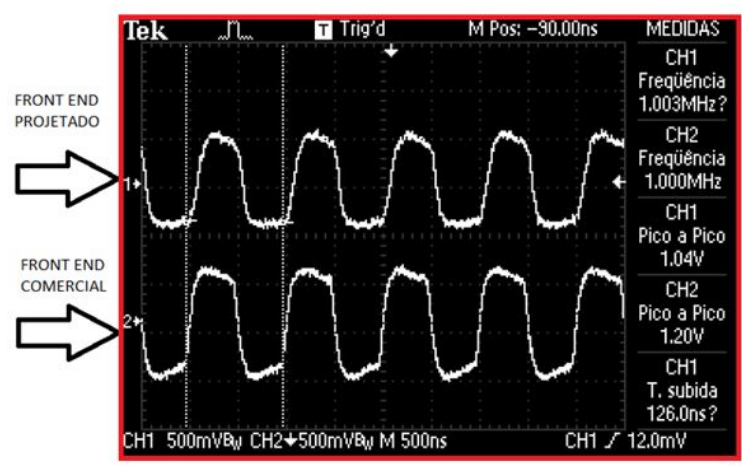

Fig. 3. Comparação entre o módulo de recepção projetado e comercial, para uma onda quadrada de $1 \mathrm{MHz}$ de frequência e com o transmissor e o receptor separados por uma distância de 2 metros.

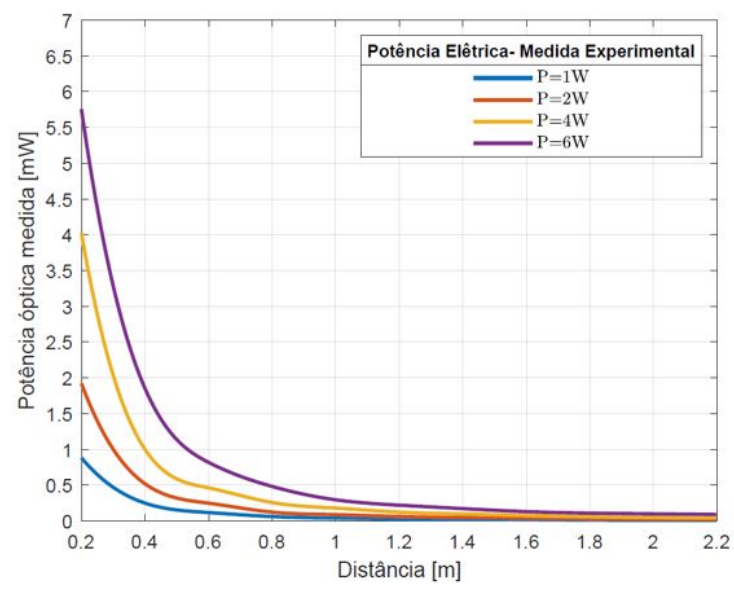

Fig. 4. Potência ótica detectada pelo sensor ótico em função da variação da distância à luminária LED e da variação da potência elétrica.

Para determinar as características de iluminância, foi utilizado a norma europeia I.S. EN 12464-1: 2011- Light and lighting - Lighting of work places - Part 1: Indoor work places [22]. Assim, para ambientes internos (escritórios) é recomendado manter a condição de iluminação em 500 lux (min 300 lux). As medições fotométricas foram realizadas com um luxímetro, seguindo o mesmo cenário da potência. A Fig. 5 mostra a distribuição da iluminância. A linha preta indica a distância até a qual é garantido 500 lux para cada potência elétrica ajustada na lâmpada LED, sendo o melhor desempenho obtido a 1,6 m com $P=6 \mathrm{~W}$. Além disso, a qualidade da iluminação foi representada por cores (retângulos) de acordo com a distância $[$ verde $=$ bom, amarelo $=$ médio, vermelho $=$ ruim].

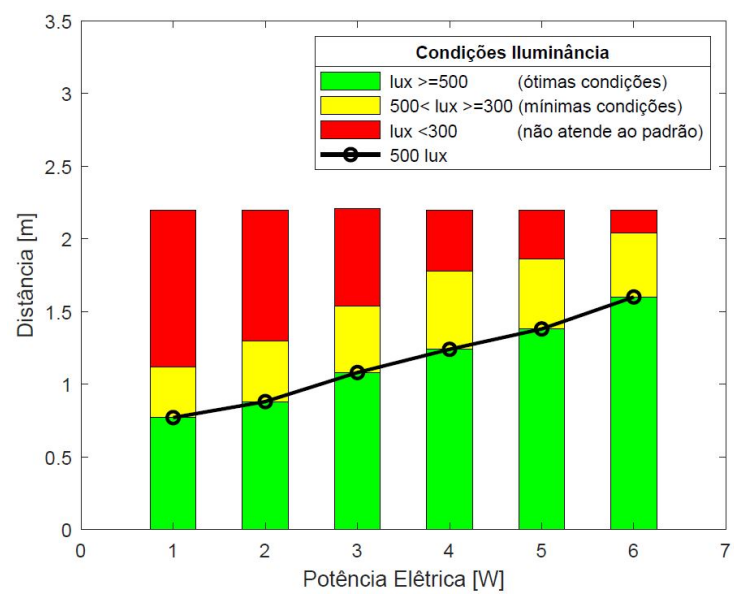

Fig. 5. Iluminância detectada pelo luxímetro em função da variação da distância à luminária LED e da variação da potência elétrica.

\section{Transmissão de dados}

Com emprego dos módulos Tx-Rx foi avaliada a melhor condição operacional de transmissão no enlace VLC, em que os dados podem ser recuperados a uma taxa de erro de $10^{-3}$, ao mesmo tempo em que se manteve a condição de iluminação determinada pela norma. Para a transmissão de dados, foram gerados códigos OOK NRZ e OFDM 4-QAM no Matlab; os quais foram carregados em um gerador de forma de onda arbitrária (AWG) e transmitidos pelo enlace Tx-Rx. Os dados recebidos foram analisados offline. Na Fig.6 é apresentada a configuração usada nos experimentos.

Medições para o sistema com modulação OOK e OFDM foram realizadas em um cenário LOS a uma distância de até 2,2 m entre Tx e Rx. Para ambientes internos, as distâncias de transmissão devem ser superiores a 1,6 m [23]. Foram usadas diferentes potências elétricas controladas pelo circuito Tx e aplicadas sobre a lâmpada LED para observar o melhor ponto de desempenho.

Na Fig. 7 é apresentado o desempenho do sistema de comunicação VLC, para isso a BER $=10^{-3}$ (linha tracejada em azul) foi avaliada em função da distância. Para a modulação OOK NRZ com BER $=10^{-3}$ foi garantida a distância de 1,9 m e para a modulação 4-QAM OFDM a distância de 1,7 $\mathrm{m}$ considerando-se uma potência elétrica de $6 \mathrm{~W}$ aplicada no LED. Portanto, tais resultados indicam que o ponto de funcionamento ideal com a luminária empregada é de 1,6 m. Para distâncias maiores, embora o desempenho da transmissão 
seja mantido, a iluminação ficará abaixo do recomendado pela norma.

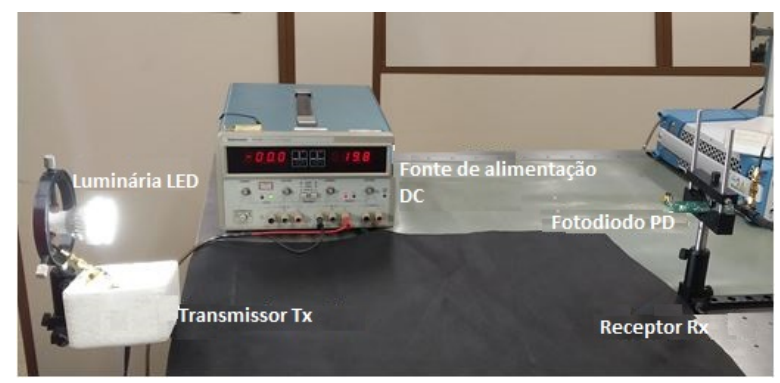

Fig. 6. Configuração experimental do enlace de comunicação VLC.

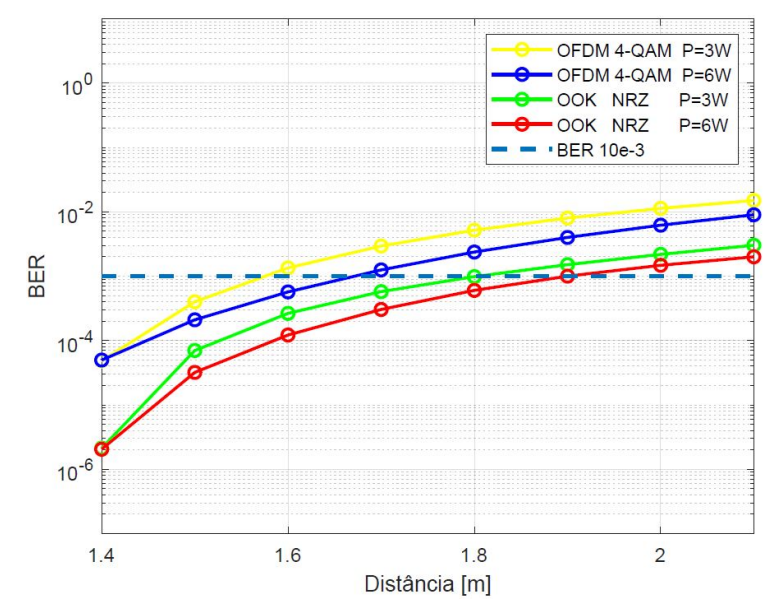

Fig. 7. BER versus distância para modulação OOK e OFDM para diferentes valores de energia elétrica

\section{CONCLUSÕES}

Os resultados obtidos mostram que os módulos Tx-Rx projetados, em conjunto com a lâmpada LED comercial utilizada, cumprem a dupla funcionalidade do VLC de transmitir informação e fornecer iluminação adequada utilizando uma luminária LED comercial polarizada com diferentes potências elétricas. O melhor caso foi apresentado quando a lâmpada é operada com $6 \mathrm{~W}$ de potência elétrica.

Uma BER menor que $10^{-3}$ é garantida em $1,7 \mathrm{~m}$ para a configuração OFDM 4-QAM e em 1,9 m para OOK. O sistema pode ser adaptado para usar outros formatos de modulação OFDM, como 16 ou 64 QAM, mas para isso devese considerar a não linearidade do LED, que não foi tratada neste trabalho. A luminária LED atendeu à recomendação de desempenho em um pequeno escritório, onde a distância entre a luminária e a superfície de trabalho para 500 lux é limitada a $1,6 \mathrm{~m}$.

\section{AgRAdecimentos}

Os autores agradecem o apoio parcial da CAPES - Coordenação de Aperfeiçoamento de Pessoal de Nível Superior Código 001 e do CNPq - Conselho Nacional de Desenvolvimento Científico e Tecnológico (processo 305714/2016-3).

Os autores agradecem o uso da infraestrutura do Laboratorio Multiusuário de Fotônica - UTFPR-CT.

\section{REFERÊNCIAS}

[1] X. Li, N. Bamiedakis, X. Guo, J. J. D. Mckendry, E. Xie, R. Ferreira, E. Gu, M.D. Dawson, R. V. Penty, and I. H. White, "Wireless Visible Light Communications Employing Feed-Forward Pre-Equalization and PAM-4 Modulation", IEEE, v. 34, no. 8, pp. 2049-2055, 2016.

[2] A. Al-Kinani, C. Wang, L. Zhou and W. Zhang, "Optical wireless communication channel measurements and models", IEEE Communications Surveys \& Tutorials, v. 20, n. 3, pp. 1939-1962, 2018.

[3] Z. Ghassemlooy, L. N. Alves, S. Zvanovec and M. Khalighi, Visible light communications: Theory and applications, Cambridge: CRC Press, 2017.

[4] D. Karunatilaka; F. Zafar, V. Kalavally, R. Parthiban, "Led based indoor visible light communications: State of the art", IEEE Communications Surveys Tutorials, v. 17, pp. 1649-1678, 2015.

[5] R. Bian, I. Tavakkolnia, and H. Haas, "15.73 Gb/s Visible Light Communication with Off-the-Shelf LEDs", Journal of Lightwave Technology, vol. 37, no. 10, pp. 2418-2424, 2019.

[6] L. Shi, W. Li, X. Zhang, Y. Zhang, G. Chen and A. Vladimirescu, "Experimental 5G New Radio integration with VLC", 25th IEEE International Conference on Electronics, Circuits and Systems (ICECS), pp 61-64, 2018, doi: 10.1109/ICECS.2018.8617851.

[7] P. Yue, L. Wu and Z. Cui, "Integrating LTE-D2D and VLC techniques to support V2V communication”, 2017 IEEE/CIC International Conference on Communications in China (ICCC), pp. 1-6, 2017.

[8] K. Siddiqi, A. D. Raza and S. S. Muhammad, "Visible light communication for V2V intelligent transport system", 2016 International Conference on Broadband Communications for Next Generation Networks and Multimedia Applications (CoBCom), pp. 1-4, 2016, doi: 10.1109/COBCOM.2016.7593510.

[9] F. C. Tosta, M. De Oliveria, A. Pohl, "Análise e caracterização de luminária LED aplicada em comunicação por luz visível", In: XXXVIII Simpósio Brasileiro de Telecomunicações e Processamento de Sinais, 2020, v. 1. p. 1-5, Florianópolis, 2020.

[10] S. Kumar, P. Singh, "A Comprehensive Survey of Visible Light Communication: Potential and Challenges", Wireless Personal Communications, vol. 109, pp. 1357-1375, 2019.

[11] J. Kahn and J. Barry, "Wireless infrared communications", Proceedings of the IEEE, vol. 85, no. 2, pp. 265-298, 1997.

[12] R. R. Iniguez, S. M. Idrus, Z. Sun, Optical Wireless Communications IR for Wireless Connectivity. CRC Press, 2008.

[13] G. Held, Introduction to Light Emitting Diode Technology and Applications. CRC Press, 2009.

[14] Z. Ghassemlooy, W. Popoola and S. Rajbhandari, Optical Wireless Communications: System and Channel Modelling with MATLAB®. CRC Press, 2012

[15] S. Dimitrov and H. Haas, Principles of LED Light Communications: Towards Networked $\mathrm{Li}-\mathrm{Fi}$, vol. 1, Cambridge: Cambridge University Press, 2015

[16] C. G. Lee, Visible Light Communication, In: Advanced Trends in Wireless Communications ,2011.

[17] P. H. Pathak, X. Feng, P. Hu and P. Mohapatra, "Visible Light Communication, Networking, and Sensing: A Survey, Potential and Challenges", in IEEE Communications Surveys \& Tutorials, vol. 17, no. 4, pp. $2047-$ 2077, Fourthquarter, 2015.

[18] T. Komine and M. Nakagawa, "Fundamental analysis for visible-light communication system using LED lights", IEEE Transactions on Consumer Electronics, vol. 50, no. 1, pp. 100-107, 2004.

[19] J. G. Proakis, M. Salehi, N. Zhou and X. Li, Communication systems engineering (Vol. 2). New Jersey: Prentice Hall, 1994.

[20] Luxeon Star LEDs, "SinkPAD-II 7 Rebel LED 40mm", (2015) [Online]. Available: www.luxeonstar.com/ansi-white-5000K-sinkpad-ii40mm-7-led-round-led-module-5581m

[21] Hamamatsu Photonics, "APD modules: C12702 series," pp. 1-5, 2017. [Online]. Available: www.hamamatsu.com/jp/en/product/type/C1270204/index.html

[22] Technical Committee CEN/TC 169 "Light and Lighting." EN 12464 1:2011. (revision of EN 12464-1:2002) Light and lighting - Lighting of work places - Part 1: Indoor work places, Brussels: CEN, 2011.

[23] IEEE, "IEEE standard for local and metropolitan area networks- part 15.7: Short-range optical wireless communications", 2018. 